\title{
Poly-D L-lactide-co-glycolide microspheres as a controlled release antigen delivery system
}

K.M. Lima and J.M. Rodrigues Júnior
Laboratório de Tecnologia Farmacêutica, Departamento de Produtos Farmacêuticos, Universidade Federal de Minas Gerais, Belo Horizonte, MG, Brasil

\section{Correspondence \\ J.M. Rodrigues Júnior \\ Departamento de Produtos \\ Farmacêuticos, UFM G \\ Av. O legário Maciel, 2360 \\ 30180-112 Belo Horizonte, MG \\ Brasil \\ Fax: + 55-31-291-9769 \\ E-mail: rodrigue@ dedalus.lcc.ufmg.br \\ Presented at the International Symposium "The Third Revolution on Vaccines: DNA Vaccines", Belo Horizonte, MG, Brasil, November 3-7, 1997. \\ Research supported by FAPEMIG and CNPq.

$\ldots \ldots \ldots \ldots \ldots \ldots \ldots$

Received November 19, 1998 Accepted December 8, 1998

\begin{abstract}
Successful vaccine application means maximum protection with minimal number of administrations. A rational development of vaccines involves studies of the nature of the antigen as well as of the adjuvant to be used to improve the immune responses. This has provided the impetus for studies to design the degradable devices and for different approaches to antigen delivery by different routes of administration. The development of controlled release systems based on polymeric devices that permit a sustained or pulsed release of encapsulated antigens has attracted much interest. Polymeric delivery systems consist of polymers that release their content continuously in a controlled manner over a period of time. The development of a biocompatible delivery system for parenteral administration offers several advantages in terms of immunoadjuvanticity over other compounds. It was found that, in contrast to other carriers, microspheres are more stable, thus permitting administration by the oral or parenteral route. In the present study, we describe the main characteristics and potentialities of this new immunoadjuvant for oral and parenteral administration.
\end{abstract}

\author{
Key words \\ - Vaccine \\ - Adjuvant \\ - Microspheres \\ - Microencapsulation \\ - Biomaterial
}

\section{Introduction}

The investigation of formulations for the controlled release in vaccine delivery is a top priority because of their potential for reducing the number of administrations required to induce protection (1-4). A rational development of vaccines involves studies of the nature of the antigen as well as the adjuvant used to improve the immune responses. With the progress in the development of new antigens resulting from biotechnology studies, the search for new adjuvants has become the main research subject for many groups who study their role and safety for therapeutical use (5-8).

In order to improve the immune responses to highly purified and, therefore, weak antigens, a wide variety of experimental immunoadjuvants have been developed but they are a long way from rendering such vaccines strong or efficient enough for their use in humans (9). The adjuvant effect may be attained by three basic mechanisms: i) a depot formation at the site of administration; ii) acting as a vehicle delivery system for targeting the antigen to immunocompetent cells, and iii) acting as immunostimulants. 
The ideal and safe adjuvant should not generate local or systemic reactions after administration. It should elicit an early, high and long-lasting immunoresponse and should be stable and chemically defined to permit reproducible manufacturing $(5,8)$. A good adjuvant needs to be able to give signals to the immunological system so that lymphocytes and phagocytes migrate to the vaccinated area (10).

However, after many decades of research for adjuvants, only aluminum and liposomes (lipid vesicles) have been approved for use in humans (9). Although many advantages may be considered for alum as adjuvant, after years of safe history, the use of aluminum-based vaccines has declined considerably due to variations in the production of alum-precipitated vaccines (8). Other limitations are their ineffectiveness for certain antigens and their inability to elicit cellmediated immune responses, particularly cytotoxic T-cell responses, which limit their application against intracellular parasites and viral infections. Also, aluminum adjuvants cannot be frozen or lyophilized (8).

Other adjuvants have been developed and a few have been evaluated in clinical trials, but most of them were never accepted for routine vaccines due to their adverse side effects. The use of liposomes as immunoadjuvants is also controversial. However, encapsulated antigens have the potential advantage of providing a higher antigen-carrying capacity. Both humoral and cell-mediated immune responses have been elicited by these systems. With the continuous hard effort of the past two decades, a considerable number of issues may yet be overcome such as shelf life and targeting specific cells.

\section{Controlled delivery systems}

The need for new adjuvants has led to the development of controlled release systems based on polymeric devices, which could permit a sustained or pulsed release of en- capsulated or entrapped antigens (11-13). This has provided the impetus for active studies to design biodegradable materials and approaches for delivery by different routes of administration (14-17). Benefits of controlled release systems are delivery to a specific site, protection of the antigen from degradation, better patient compliance and more efficient antigen dosing, which may eliminate the need for boosters.

Polymeric delivery systems consist of polymers that release their content in a controlled manner continuously over time. The development of a biocompatible delivery system for parenteral administration offers several advantages in terms of immunoadjuvanticity over other compounds. In contrast to other carriers, polymeric microspheres are stable enough to permit their administration by the topical, oral or parenteral route. This is particularly advantageous when a mucosal immune response is needed. Furthermore, the association of antigens with microspheres has been able to elicit both cellular and humoral immune response (18). The stability of this formulation under storage conditions is related to hydrolytic degradation. However, the formulations can be freeze-dried and stored as a dry powder, which can be easily reconstituted immediately before use. The main goal of polymeric microencapsulation is to coat the antigenic material with a biodegradable polymer which will protect and control the antigen delivery. The possibility of obtaining free-flowing particles with well-defined diameters from 1 to 100 micrometers offers many advantages for its manufacture and interaction with immunocompetent cells.

\section{Poly-lactide-co-glycolide microspheres}

Among the polymeric systems developed for pharmaceutical proposals, poly-lactideco-glycolide (PLGA) microspheres have been widely explored in several immuno- 
logical studies as a controlled delivery system of peptides, native and synthetic proteins and lately, nucleic acids (13-27). PLGA microspheres are composed of a sphericalshaped polymeric matrix ranging in diameter from 1 to $250 \mu \mathrm{m}$ (Figure 1). Many factors are important to formulate these systems: i) ability to release the entrapped substance in a controlled way, which is influenced by polymer molecular weight, monomer ratio and morphology (28-30); ii) particle size, which is important in terms of interaction with phagocytic cells $(12,13,31)$; iii) safety, which is related to the in vivo polymer degradation $(32,33)$, and iv) stability, both in storage and in the biological fluids $(34,35)$.

The antigen is physically entrapped into microspheres inside an injectable solid polymeric matrix. The combination of diffusion through pores and of polymer matrix biodegradation allows the control of antigen release rates. The biodegradation rate of the polymer depends on its molecular weight and it is well established that shorter chains are degraded faster $(30,36)$. After their terminal chain hydrolysis, the resulting degraded products are monomers of lactide and glycolide, which are innocuous to the body. These degraded products are eliminated by the Krebs cycle as carbon dioxide and in the urine (37). During biodegradation, the encapsulated antigen is released. Since these polymers are chemically defined, the antigen release is uniform and reproducible. This release can vary from hours to months depending on the polymer combinations.

Microsphere diameter plays an important role in the interactions with phagocytic cells. Particles smaller than $10 \mu \mathrm{m}$ may be phagocytosed faster by macrophages, which are recruited to the site of administration after subcutaneous injection, and particles larger than $10 \mu \mathrm{m}$ act as a depot releasing the antigens in a second step $(13,16)$. We also have to consider the fate of these particles across the digestive tract to be taken up by

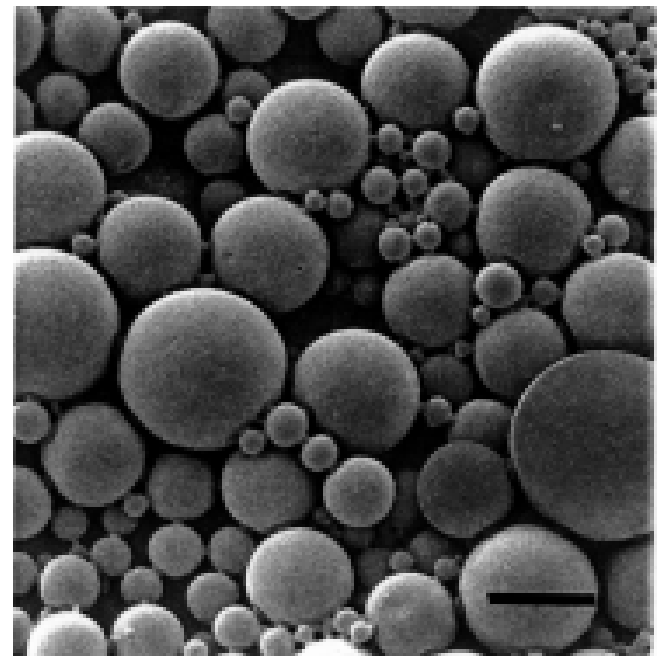

the $M$ cells of the Peyer's patches, when administered orally, since this could play a role by facilitating the antigen presentation to the immunocompetent cells and consequently the elicitation of an effective mucosal immune response. Enhancement of the stability of macromolecules may also be attained since they are protected from enzymes or other factors that could compromise the stability of the antigens.

Another important factor in favor of this new immunoadjuvant is related to its safety. These polymers have a long history as a safe material used in the composition of sutures and implants. This fact provided the basis for injectable delivery systems now used by 300,000 patients annually for treating advanced prostate cancer, endometriosis or precocious puberty (38).

Polymer selection is the most important step in the manufacture of microspheres because it critically influences their rate of biodegradation and hence devices with shortor long-lasting action can be constructed. Nowadays, several biocompatible polymers are commercially available. By changing the homopolymer ratio, different physicochemical compositions can influence its degradability and permeability, resulting in degradation times ranging from weeks up to several months depending on the shape, size and porosity of the device (Table 1). These pa-
Figure 1 - Scanning electronic photomicrograph of PLGA microspheres obtained by the multiple emulsion $\mathrm{W} / \mathrm{O} / \mathrm{W}$ method. Bar $=5 \mu \mathrm{m}$ 
Table 1 - Physicochemical characteristics and biodegradation time of poly-lactide and co-polymers.

*Biodegradation time depends on the formulation, porosity, surface area and polymer molecular weight. Adapted from Ref. 35.

\begin{tabular}{lccc} 
Polymer & Crystallinity & Glass transition & $\begin{array}{c}\text { Biodegradation } \\
\text { time (months)* }\end{array}$ \\
\hline Poly (L-lactide) & Crystalline & $45-60^{\circ} \mathrm{C}$ & $18-24$ \\
Poly (D,L-lactide) & Amorphous & $50-65^{\circ} \mathrm{C}$ & $12-16$ \\
50:50 Poly (D,L-lactide-co-glycolide) & Amorphous & $40-55^{\circ} \mathrm{C}$ & 2 \\
85:15 Poly (D,L-lactide-co-glycolide) & Amorphous & $45-60^{\circ} \mathrm{C}$ & 5
\end{tabular}

rameters can be easily monitored using different polymer and copolymer compositions and controlling the variables during the manufacture process. Since the amorphous polymers are more permeable, poly-DL-lactide acid (DL-PLA), which is less amorphous than PLGA copolymers, has a slower degradation rate, usually over several months. The combination of particles with different diameters and polymer composition in the same formulation has permitted to establish the concept of the single-dose vaccine (1), which can be programmed to mimic the reinforcement dosages, inducing protection with a minimal number of administrations (Figure 2). Finally, PLA and its copolymers have

Figure 2 - The single-dose vaccination model based on PLGA microspheres. Adapted from Ref. 1.

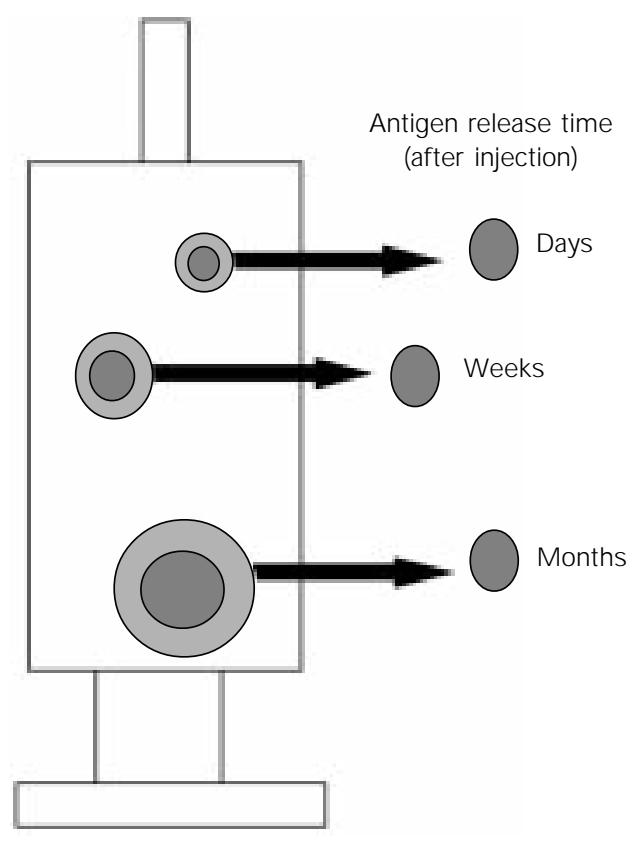

proved to be biocompatible and produce little or no local or systemic toxicity $(39,40)$.

PLGA subcutaneously administrated acts by means of three mechanisms: i) a depot formation at the site of administration; ii) targeting antigens to antigen-presenting cells, since it has been well described that macrophages are recruited to the site of the injection, or adherence to the Peyer's patches, which could facilitate the antigen presentation $(41,42)$, and iii) protection of the antigen by storage, with a slow release of the remaining antigens that could eliminate the need for a booster $(43,47)$.

\section{Microsphere preparation}

PLGA microspheres can be obtained by two main methods: simple emulsification $(\mathrm{O} / \mathrm{W})$ or multiple water-in-oil-in-water $(\mathrm{W} /$ $\mathrm{O} / \mathrm{W}$ ) emulsion followed by solvent elimination. The choice of method depends on the physical and chemical characteristics of the antigen, permitting the matrix entrapment of both lipophilic and hydrophilic molecules.

In the first case, an emulsion is formed by dissolving (or dispersing) the antigen in an organic solvent immiscible in water (methylene chloride, chloroform or ethyl acetate) containing the polymer, under strong mechanical agitation. This emulsion may be stabilized by a surfactant added to the aqueous phase. The solvent is eliminated by evaporation at room temperature, followed by washing and freeze-drying.

The multiple emulsion method involves water-in-oil-in-water emulsification (16,31). The inner aqueous phase containing the hydrophilic substances is obtained after emulsification with the immiscible organic solvent-containing polymer under strong mechanical agitation. This first emulsion is stabilized by the addition of an aqueous solution containing a surfactant (e.g., poly vinyl alcohol) and is further homogenized to produce a $\mathrm{W} / \mathrm{O} / \mathrm{W}$ double emulsion. This double emulsion is gently stirred with a homog- 
enizer at room temperature for solvent evaporation. The microspheres are collected by centrifugation, washed with water and freezedried. The composition of the aqueous phase as well as the surfactant applied plays an important role in the pattern of antigen release since porosity and water permeability will be dependent on these factors. A mixture of hydrophilic and lipophilic molecules can also be successfully entrapped by using the $\mathrm{W} / \mathrm{O} / \mathrm{W}$ method (48).

Both of these methods allow high levels of antigen entrapment. The particles are characterized by determining the antigen entrapment rate, their average diameter, porosity and in vitro antigen release kinetics in appropriate medium. The maintenance of immunogenicity after antigen contact with organic solvents is also an important aspect to consider. Many studies have indicated that the antigenic properties and the structure of the proteins can be preserved during entrapment $(26,44,49-53)$. Another important aspect is related to the possibility of scaling up the process under aseptic conditions, allowing the preparation of a pyrogen-free and sterile product (54).

\section{Considerations about PLGA microsphere biocompatibility}

Polymeric microspheres have attracted much attention because of their biocompatible characteristics. The phagocytosis of biodegradable and nonbiodegradable particles has been reported to depend on their size, surface charge and hydrophobicity $(55,56)$. After subcutaneous administration, PLGA microspheres ranging in diameter from 1 to $10 \mu \mathrm{m}$ are readily phagocytosed by macrophages recruited to the site of injection, thereby providing an intracellular delivery of the antigen. This mechanism may enhance antibody responses and consequently decrease the required antigen dose. On the other hand, particles larger than $10 \mu \mathrm{m}$ in diameter would remain as a depot at the site of injection providing a sustained release of antigen. Improving their hydrophobicity can increase phagocytosis of the particles, whereas microsphere preparations with different compositions of PLA and PLGA do not alter the extent of phagocytosis. However, precoating microspheres with opsonins can enhance phagocytosis (55). The intracellular fate of these particles is dependent on their composition. The rate of microsphere degradation inside cells could be controlled by changing the molecular weight and the monomer composition. PLGA microspheres are readily degraded releasing the entrapped molecules. Small particles of $200 \mathrm{~nm}$ in diameter are readily phagocytosed by Kupffer cells and reach the lysosomial compartment in liver tissues after intravenous administration, as demonstrated by transmission electron microscopy (56).

The relationship between the maximal dose of polymer and its implications in the intracellular residential time is not yet clear. In some reports of immunization studies, the entrapped protein:polymer ratio is very low, requiring administration of a huge amount of microspheres to attain the desirable antigen dose. It is well documented that the antigen and adjuvant doses interfere with the immune responses. Studies conducted with subcutaneous implants indicate that the physicochemical characteristics of PLA and PLGA polymers play a decisive role in the in vivo degradation time and also in the local inflammatory reaction $(32,33,39)$. These results highlight an important aspect to be considered in the development of microspheres as carriers, i.e., the dose of polymer. We focused our studies on the clarification of the local responses after subcutaneous administration of microspheres, using an air pouch model in rats. We observed that $6 \mathrm{~h}$ after the administration of a single dose of $125 \mathrm{mg}$ or a higher dose of $625 \mathrm{mg}$ of polymer per kg rat body weight, $14.3 \times 10^{3}$ and $31.5 \times 10^{3}$ cells were recruited to the air pouch, respectively. Seven days after injec- 
tion, the number of cells decreased conspicuously without a significant difference between the treated groups and the control group treated with saline only. Histological analysis allowed us to identify an organic reactivity in the injected area characteristic of macrophage infiltration. Using soluble and particulate Leishmania antigens as a model, we found that the mononuclear infiltrate obtained at the injection site was larger with antigen-loaded microspheres as compared to unloaded ones. No granulocytic cell infiltration was observed. Higher doses (250 and $625 \mathrm{mg} / \mathrm{kg}$ ) provoked the formation of a fibrovascular capsule surrounding the microspheres. In contrast, after administration of lower doses this reaction was not observed and PLGA microspheres were found to be completely degraded one month after injection. We selected the maximal polymer dose of $150 \mathrm{mg} / \mathrm{kg}$ to design our experimental protocols.

\section{Systemic immunization}

The diameter of the particles plays an important role in the induction of protection by parenteral immunization. In fact, when ovalbumin was adsorbed to or entrapped in PLGA microspheres of different diameters, drastic differences were observed in the antibody responses $(12,13)$. Two weeks after immunization with a single dose by the subcutaneous route, the serum IgG antibody response to ovalbumin was significantly greater than the response to soluble ovalbumin. This response was more significant for particles of $1.5 \mu \mathrm{m}$ than for particles larger than $73 \mu \mathrm{m}$. Interestingly, the level of antibodies remained high even one year after injection (16). Uchida et al. (31) reported similar results showing the superior efficacy of microspheres over alum. Vaccine formulations prepared by simple mixing of blank microspheres (without antigens) and ovalbumin exhibited low primary immune responses, which were only elevated by boosting (45).
Three batches of PLA and PLGA microspheres were used to investigate the single dose vaccine delivery by incorporating tetanus toxoid (18). Its comparison with aluminum hydroxide as immunoadjuvant provided data to support the superior efficacy of PLGA microspheres to elicit $T$ cell and antibody responses after subcutaneous administration. These results were confirmed by Walker et al. (57). The cellular and antibody responses of mice to tetanus toxoid were compared after subcutaneous administration of the toxoid alone or incorporated into aluminum hydroxide and PLGA microspheres. The safety of a similar vaccine was demonstrated in rats (40).

The entrapment of a synthetic peptide in PLGA microspheres was evaluated by Partidos et al. (23). Intraperitoneal immunization with particles smaller than $10 \mu \mathrm{m}$ containing a chimeric peptide constructed by synthesis of a potential B cell site induced anti-peptide antibody responses after a single dose. This single intraperitoneal administration protocol was also applied to induce protection against Bordetella pertussis respiratory infection in mice (26). Although, PLGA microspheres containing pertussis fimbrae elicited lower levels of serum antibody than those produced by alhydrogel-containing antigen, both formulations protected against intranasal infection by $B$. pertussis.

The magnitude of the immune response induced by peptides is comparable or superior to that induced by peptide emulsified in complete Freund's adjuvant (58). In vitro, peptides (carrying an immunodominant $\mathrm{T}$ helper cell epitope delineated from the rabies virus nucleoprotein) incorporated into PLGA microspheres induced the proliferation of a peptide-specific $T$ cell line. After subcutaneous immunization of mice, the immune response induction was related to the nature of the polymer.

Other encouraging trials have been conducted providing data to confirm the superior efficacy of this system over other adju- 
vants in a birth control vaccine (25), HIV-1 vaccine $(52,54)$, rabies virus nucleoprotein (58), malaria antigen (59) and type A botulism (60).

\section{Mucosal immunization}

New approaches to vaccine development have become possible after a common mucosal defense system was recognized where an antigen interacting with localized lymphoid tissue could stimulate IgA precursor cells that could migrate to other mucosal surfaces $(12,13,61)$. The mucosal immune system displays a unique ability to respond to an array of immunogens presented by the respiratory and oral routes. Oral vaccines are often more desirable than other routes because of easy administration to large populations and a reduced number of side effects (62). Since PLGA microspheres are readily absorbed by the Peyer's patches, they have considerable potential as a vehicle for oral immunization. They are taken up by modified epithelial cells (M cells) and transported to the lymphoid tissue where they encounter antigen-presenting cells including macrophages, dendritic cells and B cells. So, the use of microspheres has two advantages: i) protection from low $\mathrm{pH}$ and from proteases (since the antigen and/or adjuvant are entrapped in the polymer matrix, they are protected from both gastric and gastrointestinal proteolysis), and ii) targeting to IgA inductive sites.

It was found that peroral immunizations with a toxoid vaccine of staphylococcal enterotoxin B encapsulated in 1-10 $\mu \mathrm{m}$ PLGA microspheres stimulated circulating IgM, IgG and $\operatorname{IgA}$ antitoxin antibodies in mice. A disseminated mucosal IgA response was also observed. Systemic immunization was effectively primed for a mucosal IgA response when a booster was administered by the oral or intratracheal route, indicating that under these experimental conditions the systemic immunization did not induce tolerance to or down-regulation of a subsequent mucosal antibody response. Nonencapsulated controls did not elicit any significant response. Microspheres less than $5 \mu \mathrm{m}$ in diameter were effectively taken up by Peyer's patches and carried by macrophages to the mesenteric lymph nodes and spleen. On the other hand, microspheres in the range of 5-10 $\mu \mathrm{m}$ remained in the Peyer's patches throughout the 35 days of the experiment. Microspheres larger than $10 \mu \mathrm{m}$ in diameter were not adsorbed at any point in the gastrointestinal tract (13).

The entrapment of a branched peptide immunogen representing a portion of the principal neutralizing determinant of HIV-1 has been developed for oral and combined oral and subcutaneous immunization against HIV. Under aseptic conditions a pyrogenfree and sterile preparation was obtained. The system showed high levels of both serum IgG and neutralizing antibodies against HIV in guinea pigs in both protocols. The authors proposed the formulation for clinical trials $(52,54)$. Recently, it was demonstrated that immunization with a recombinant HIV envelope protein entrapped in PLGA microspheres induced consistent HIVspecific CD4+ and CD8+ T-cell responses in mice. Cytotoxic T lymphocyte (CTL) responses were detected after a single systemic immunization with gp120 entrapped in microparticles; when given by the intranasal route these microparticles induced HIVspecific CD8+ CTL and secretory IgA. The induction of Th1 cells was observed after generation of CD4 $+\mathrm{T}$ cells that secreted moderate to high levels of interferon- $\gamma$ following immunization with gp120 entrapped in microparticles (63).

Entrapped plasmid DNA was recently proposed for oral administration (27). Entrapped DNA expressing the insect protein luciferase under the transcriptional control of the human cytomegalovirus promoter was administered by the oral and intraperitoneal routes. Entrapment increased the DNA sta- 
bility and stimulated the secretion of $\operatorname{IgA}$, IgG and IgM after oral administration. On the other hand, only the IgM and IgG responses were significant after intraperitoneal administration.

\section{Concluding remarks}

PLGA microspheres with an incorporated antigen represent a good antigen delivery system for both cellular and humoral responses. Further efforts are needed to elaborate an effective controlled release system for antigens. The promising use of PLA and PLGA microspheres has been confirmed by experimental and clinical trials. The question whether pulsed or continuous antigen release provides the better immune responses remains to be clarified. The easy manufacture of microspheres and the possibility of administration by different routes offer the additional advantage of their use as a pharmaceutically acceptable adjuvant for vaccines. These findings may have major implications for the design of novel vaccine delivery strategies.

\section{References}

1. Aguado MT (1993). Future approaches to vaccine development: single-dose vaccines using controlled-release delivery systems. Vaccine, 11: 596-597.

2. Khan MZI, Opdebeeck JP \& Tucker IG (1994). Immunopotentiation and delivery systems for antigens for single-step immunization: recent trends and progress. Pharmaceutical Research, 1: 2-11.

3. Powell MF \& Newman MJ (1994). Vaccine Design: The Subunit and Adjuvant Approach. Plenum Publishing Corporation, New York.

4. Cleland J L (1995). Design and production of single-immunization vaccines using polylactide polyglycolide microsphere systems. In: Powell MF \& Newman MJ (Editors), Vaccine Design: The Subunit and Adjuvant Approach. Plenum Publishing Corporation, New York, 439-462.

5. Bomford R (1989). Adjuvants for anti-parasite vaccines. Parasitology Today, 5: 4146.

6. Allison AC \& Byars NE (1991). Immunological adjuvants: desirable properties and side effects. Molecular Immunology, 28: 279-284.

7. Audibert FM \& Lise LC (1993). Adjuvants: current status, clinical perspectives and future prospects. Immunology Today, 14: 281-284.

8. Gupta RK \& Siber GR (1995). Adjuvants for human vaccines - current status, problems and future prospects. Vaccine, 13: 1263-1276.

9. Gregoriadis G (1998). Genetic vaccines: strategies for optimization. Pharmaceutical Research, 15: 661-669.

10. Gizurarson S (1996). Optimal delivery of vaccines - clinical pharmacokinetic con- siderations. Clinical Pharmacokinetics, 30: 1-15.

11. Partidos $C D$, Vohra $P$, J ones $D$, Farrar $G \&$ Steward MW (1997). CTL responses induced by a single immunization with peptide encapsulated in biodegradable microparticles. J ournal of Immunological Methods, 7: 143-151.

12. Eldridge J H, Staas J K, Meulbroek J A, Tice TR \& Gilley RM (1991). Biodegradable microspheres as a vaccine delivery system. Molecular Immunology, 28: 287-294.

13. Eldridge J $\mathrm{H}$, Staas J $\mathrm{K}$, Dexiang $\mathrm{C}$, Preston AM, Tice TR \& Gilley RM (1993). New advances in vaccine delivery systems. Seminars in Hematology, 4: 16-25.

14. Mestecky J \& Eldridge J H (1991). Targeting and controlled release of antigens for the effective induction of secretory antibody responses. Current Opinion in Immunology, 3: 492-495.

15. Allaoui-Attarki K, Fattal E, Pecquet $S$, Trolle S, Chachaty E, Couvreur $P \&$ Andremont A (1998). Mucosal immunogenicity elicited in mice by oral vaccination with phosphorylcholine encapsulated in poly (D,L-lactide-co-glycolide) microspheres. Vaccine, 16: 685-691.

16. O'Hagan DT, J effery H \& Davis SS (1993). Long-term antibody responses in mice following subcutaneous immunization with ovalbumin entrapped in biodegradable microparticles. Vaccine, 11: 965-969.

17. O'Hagan DT, Rafferty D, Wharton $S \&$ Illum L (1993). Intravaginal immunization in sheep using a bioadhesive microsphere antigen delivery system. Vaccine, 11: 660664.

18. Men $Y$, Thomasin C, Merkle HP, Gander B \& Corradin G (1995). A single adminis- tration of tetanus toxoid in biodegradable microspheres elicits $\mathrm{T}$ cell and antibody response similar or superior to those obtained with aluminum hydroxide. Vaccine, 7: 683-689.

19. Santiago N, Milstein S, Rivera T, Garcia E, Zaidi T, Hong H \& Bucher D (1993). Oral immunization of rats with proteinoid microspheres encapsulating influenza virus antigens. Pharmaceutical Research, 8: 1243-1247.

20. Gander B, Thomasin C, Merkle HP, Men Y $\&$ Corradin G (1993). Pulsed tetanus toxoid release from PLGA-microspheres and its relevance for immunogenicity in mice. In: Proceedings of the International Symposium of Controlled Release Bioactive Materials. Washington DC, 20: 65-66.

21. Hazrati AM, Lewis DH, Atkins TJ, Stohrer RC, McPhilips CA \& Little J E (1993). Salmonella enteritidis vaccine utilizing biodegradable microspheres. Proceedings of the International Symposium of Controlled Release Bioactive Materials. Washington DC, 20: 101-102.

22. Almeida AJ, Alpar $\mathrm{HO} \&$ Brown RW (1993). Immune response to nasal deliveny of antigenically intact tetanus toxoid associated with poly(L-lactic acid) microspheres in rats, rabbits and guinea-pigs. J ournal of Pharmacy and Pharmacology, 45: 198-203.

23. Partidos CD, Shaw DM, Gander B, Merkle HP, Howard CR \& Steward MW (1994). Induction of antibody responses to a synthetic peptide entrapped in biodegradable microparticles. Vaccine Research, 4: 203209.

24. Vordermeier HM, Coombes AGA, J enkins P, McGee J P, O'Hagan DT, Davis SS \& 
Singh M (1995). Synthetic delivery system for tuberculosis vaccines: immunological evaluation of the $M$. tuberculosis $38 \mathrm{kDa}$ protein entrapped in biodegradable PLG microparticles. Vaccine, 16: 1576-1582.

25. Singh M, Singh O \& Talwar GP (1995). Biodegradable delivery system for a birth control vaccine: Immunogenicity studies in rats and monkeys. Pharmaceutical Research, 12: 1796-1800.

26. J ones $D H, M c B$ ride BW, J effery $H$, O'Hagan DT, Robinson A \& Farrar GH (1995). Protection of mice from Bordetella pertussis respiratory infection using microencapsulated pertussis fimbriae. Vaccine, 7: 675-681.

27. J ones DH, Comis S, McDonald S, Clegg J C \& Farrar GH (1997). Poly(DL-lactide-coglycolide)-encapsulated plasmid DNA elicits systemic and mucosal antibody responses to encode protein after oral administration. Vaccine, 15: 814-817.

28. Pistner H, Gutwald R, Ordung R, Reuther J \& Muhling J (1993). Poly(l-lactide): a long-term degradation study in vivo. I. Biological results. Biomaterials, 14: 671-677.

29. Dorta MJ , Munguía O \& Llabrés M (1993). Effects of polymerization variables on PLGA properties: molecular weight, composition and chain structure. Intemational J oumal of Pharmaceutics, 100: 9-14.

30. Park TG (1994). Degradation of poly(D,Llactic acid) microspheres: effect of molecular weight. J ournal of Controlled Release, 30: 161-173.

31. Uchida T, Goto S \& Foster T (1994). Particle size studies for subcutaneous delivery of poly(lactide-co-glycolide) microspheres containing ovalbumin as vaccine formulation. J ournal of Pharmacy and Phamacology, 47: 556-560.

32. Pekarek KJ , Dyrud MJ , Ferrer K, J ong YS \& Mathiowitz $E$ (1996). In vitro and in vivo degradation of double-walled polymer microspheres. J ournal of Controlled Release, 40: 169-178.

33. Spenlehauer $G$, Vert $M$, Benoit JP \& Boddaert A (1989). In vitro and in vivo degradation of poly(D,L-lactide/glycolide) type microspheres made by solvent evaporation method. Biomaterials, 10: 557-563.

34. Langer R (1996). Controlled release of a therapeutic protein. Nature Medicine, 7: 742-743.

35. Lewis DH (1990). Controlled release of bioactive agents from lactide/glycolide polymers. In: Chasin M \& Langer R (Editor), Biodegradable Polymers as Drug De- livery Systems. Marcel Dekker, New York, 1-43.

36. Park TG, Lu W \& Crotts G (1995). Importance of in vitro experimental conditions on protein release kinetics, stability and polymer degradation in protein encapsulated poly (D,L-lactic acid-co-glycolic acid) microspheres. J ournal of Controlled Release, 33: 211-222.

37. Bazile DV, Ropert C, Huve P, Verrecchia T, Marland M, Frydman A, Veillard M \& Spenlehauer G (1992). Body distribution of fully biodegradable 14C-poly(lactic acid) nanoparticles coated with albumin after parenteral administration to rats. Biomaterials, 13: 1039-1102.

38. Langer R (1998). Drug delivery and targeting. Nature, 392 (Suppl): 5-10.

39. Visscher GE, Robison RL, Maulding HV, Fong JW, Pearson JE \& Argentieri GJ (1986). Biodegradation of and tissue reaction to poly(D,L-lactide) microcapsules. J ournal of Biomedical Materials Research, 20: 667-676.

40. Chaudhury $M R$, Sharma $K \&$ Giri $D K$ (1996). Poly(D,L-lactice) glycolide polymer microsphere entrapped tetanus toxoid: safety evaluation in Wistar rats. Human and Experimental Toxicology, 15: 205207.

41. O'Hagan DT (1996). The intestinal uptake of particles and the implications for drug and antigen delivery. J oumal of Anatomy, 19: 477-482.

42. Beier R \& Gebert A (1998). Kinetics of particle uptake in the domes of Peyer's patches. American J ournal of Physiology, 275: G130-G137.

43. An-Cheng C \& Gupta RK (1996). Stabilization of tetanus toxoid in poly(DL-lactic-coglycolic acid) microspheres for the controlled release of antigen. J ournal of Pharmaceutical Sciences, 85: 129-132.

44. Schwendesman SP, Constantino HR, Gupta RK, Tobio M, Chang AC, Alonso MJ , Siber GR \& Langer R (1996). Strategies for stabilising tetanus toxoid toward the development of a single-dose tetanus vaccine. Developments in Biological Standardization, 87: 293-306.

45. Coombes AG, Lavelle EC, J enkins PG \& Davis SS (1996). Single dose, polymeric, microparticle-based vaccines: the influence of formulation conditions on the magnitude and duration of the immune response to a protein antigen. Vaccine, 14: 1429-1438.

46. Crotts G \& Park TG (1997). Stability and release of bovine serum albumin encapsulated within poly(D,L-lactide-co-glyco- lide) microparticles. J ournal of Controlled Release, 44: 123-134.

47. J ohansen $P$, Men $Y$, Audran R, Corradin G, Merkle HP \& Gander B (1998). Improving stability and release kinetics of microencapsulated tetanus toxoid by co-encapsulation of additives. Pharmaceutical Research, 15: 1103-1110

48. Lima KM, Chiarini-Garcia H, Bambirra EA, Afonso LCC \& Rodrigues J únior J M (1998). Development and characterization of Leishmania major antigens-loaded PLGA microspheres. Proceedings of the III PHARMATECH: New Perspectives in Drug Delivery Systems, J uly 26-29, Belo Horizonte, MG, Brasil, 103-104.

49. McGee JP, Davis SS \& O'Hagan DT (1994). Zero order release of protein from poly(D,L-lactide-co-glycolide) microparticles prepared using a modified phase separation technique. J ournal of Controlled Release, 34: 77-86.

50. Yeh $M-K$, Coombes AGA, J enkins PG \& Davis SS (1995). A novel emulsificationsolvent extraction technique for production of protein loaded biodegradable microparticles for vaccine and drug delivery. J oumal of Controlled Release, 33: 437445.

51. Kofler N, Ruedl C, Klima J, Recheis $H$, Bock G, Wick G \& Wolf H (1996). Preparation and characterization of poly-(D,Llactide-co-glycolide) and poly-(L-lactic acid) microspheres with entrapped pneumotropic bacteria antigens. J ournal of Microbiological Methods, 192: 25-35.

52. Cleland J L, Lim A, Barrón L, Duenas ET \& Powell MF (1997). Development of a single-shot subunit vaccine for HIV-1: part 4. Optimizing microencapsulation and pulsatile release of MN rgp120 from biodegradable microspheres. J oumal of Controlled Release, 47: 135-150.

53. Allaoui-Attarki K, Pecquet $S$, Fattal $E$, Trolle S, Chachaty E, Couvreur P\& Andremont A (1997). Protective immunity against Salmonella typhimurium elicited in mice by oral vaccination with phosphorylcholine encapsulated in poly(DL-lactideco-glycolide) microspheres. Infection and Immunity, 65: 853-857.

54. O'Hagan DT, McGee J P, Boyle R, Gumaer D, Li X-M, Potts B, Wang CY \& Koff WC (1995). The preparation, characterization and pre-clinical evaluation of an orally administered HIV-1 vaccine, consisting of a branched peptide immunogen entrapped in controlled release microparticles. J ournal of Controlled Release, 36: 75-84.

55. Tabata Y \& Ykada Y (1988). Macrophage 
phagocytosis of biodegradable microspheres composed of L-lactic acid/glycolic acid homo- and copolymers. J ournal of Biomedical Materials Research, 22: 837858.

56. Rodrigues J r J M, Croft SL, Fessi H, Bories $C \&$ Devissaguet J Ph (1994). The activity and ultrastructural localization of primaquine-loaded poly(D,L-lactide) nanoparticles in Leishmania donovani-infected mice. Tropical Medicine and Parasitology, 45: 223-228.

57. Walker KB, Xing DK, Sesardic D \& Corbel MJ (1998). Modulation of the immune response to tetanus toxoid by polylactidepolyglycolide microspheres. Developments in Biological Standardization, 92: 259-267.

58. Ertl HC, Varga I, Xiang ZQ, Kaiser K,
Stephens L \& Otvos J r L (1996). Poly(DLlactide-co-glycolide) microspheres as carriers for peptide vaccine. Vaccine, 14: 879 885.

59. Men $Y$, Tamber H, Audran R, Gander B \& Corradin $G$ (1997). Induction of a cytotoxic T lymphocytes response by immunization with a malaria specific CTL peptide entrapped in biodegradable polymer microspheres. Vaccine, 15: 1405-1412.

60. Whalen RL, Dempsey DJ , Thompson LM, Bucknell K, Kunitomo R, Okazaki Y \& Harasaki H (1996). Microencapsulated vaccines to provide prolonged immunity with a single administration. American Society for Artificial Internal Organs Transactions, 46: M649-M654.

61. Santiago N, Hass $S \&$ Baughman RA (1994). Vehicles for Oral Immunization.
In: Powell MF \& Newman MJ (Editors), Vaccine Design: The Subunit and Adjuvant Approach. Plenum Publishing Corporation, New York, 413-438.

62. Shalaby WSW (1995). Development of oral vaccines to stimulate mucosal and systemic immunity: barriers and novel strategies. Clinical Immunology and Immunopathology, 74: 127-134.

63. Moore $A$, McGuirk $P$, Adams $S$, J ones WC, McGee J P, O'Hagan DT \& Mills KH (1995). Immunization with a soluble recombinant HIV protein entrapped in biodegradable microparticles induces HIVspecific CD8+ cytotoxic T lymphocytes and CD4+ Th1 cells. Vaccine, 13: 17411749. 